EVS28

KINTEX, Korea, May 3-6, 2015

\title{
Cost Reduction through Cell Design Optimization for Vehicle Requirements - From Active Material to Vehicle Product Portfolios
}

\author{
Matthias Tschech and Prof. Dr.-Ing. Thomas Vietor \\ Technische Universität Braunschweig, Institute for Engineering Design
}

\begin{abstract}
The cost situation for lithium-ion batteries is one of the key limitations for the market potential of electric vehicles and has been covered by several authors from the industry and science sector. This work addresses the relation between active material properties, cell design and vehicle requirements. The results of this investigation show that the efficient use of the cell properties in the vehicle application will be decisive for the competitiveness of OEMs and battery suppliers.

The center of the research is a cell model in which different active material properties, cell formats and electrode layouts can be implemented flexibly. Within a constant volume of a standardized cell housing the variation of the electrode loadings leads to relationships between the storable energy and the power of the cell. The costs determined for each specific cell design then allow describing the relation between the power to energy ratio of a cell and its energy specific costs for current and future materials.

The optimal cost situation is reached when the P/E-ratio of the cell matches the required P/E-ratio of the storage system. In a broad vehicle portfolio this means a specific cell would be required for each car project. This potentially large number of cell types seems unfavorable for OEMs to handle. Therefore a genetic algorithm optimization is applied to determine the cost-optimal number and specifications of cells to address a certain vehicle portfolio. For these optimizations further restrictions such as voltage level limitations are considered as well.

The tool derived from these considerations can support OEMs as well as cell \& material suppliers to find the optimal modular kit for their lithium-ion cell strategy considering individual customer requirements.

Keywords: Lithium-Ion Cell Design, Vehicle Requirements, Cost Optimization, Modular Kit, Genetic Algorithm

\section{Introduction}

The cost situation of lithium-ion batteries is one of the most critical barriers for a significant market penetration of electric vehicles. The development of cost per energy (e.g. $€ \mathrm{kWh})$

based on the anticipated performance enhancement of upcoming generations of lithium-ion battery materials was analyzed by several studies [1]-[5]. In this paper, the cost effects of energy and power requirements in electric drivetrains are investigated. Therefore, relations between cost and function are quantified in a flexible bottom-up cell
\end{abstract}


model. In this approach the term function is defined as customer relevant performance of a cell such as power and storable energy, whereas cost is the monetary effort related to the respective cell.

To account for the dynamic technology environment the model allows considering different lithium-ion cell technology set-ups (housings, active materials, etc.). The objective of the technique depicted in this paper is to make use of the cost per function relations to:

1) Evaluate the stand-alone cell cost of a vehicle portfolio, dependent on the cell technology

2) Identify the ideal number of cell variants and power to energy ratios (P/E-ratios) to serve a vehicle portfolio in a cost-optimal way.

3) Determine the optimal cell size to serve a vehicle portfolio cost efficiently while accounting for system restrictions such as voltage levels.

\section{Cell Model}

In the first step, a cell model is developed which allows to approximate the cell performance (storable energy and available power) based on a bill of material (BOM). The component and material parameter description in the BOM allows determining:

1) The cost of the cell based on material and production cost data.

2) The cost and performance effect of applying new materials

Inputs for the cell model are geometric dimensions of different cell formats, material properties and results from investigations of sample cells.

\subsection{Cell Design}

The analyzed cell geometries are the VDA standardized prismatic cell formats [6] and the 18650-consumer format. The simplified assumption is that the cell performance (power focus vs. energy focus) is determined by the thickness of the electrode. A constant utilization of the inner cell volume is assumed. This implies that the change of the electrode thickness at the same time leads to a change of the electrode surface. Smaller thicknesses increase the electrode surfaces; higher thicknesses reduce the electrode surface and enlarge the volume share that is filled by active material.

In a constant cell volume, the thickness of the anode $D_{a}$ can be described as a function of the thickness of the cathode $D_{c}$. In order to meet the required capacity ratio between anode and cathode, the specific active material capacities $c_{\text {spec,am }}$, the active material mass share of the electrode $m_{a m}$, the material densities $\rho$ and the electrode porosities $\varepsilon$ need to be taken into account. [7]

$D_{a}=f\left(D_{c}, c_{\text {spec }, a m}, \rho, m_{a m}, \varepsilon\right)$

By varying the thickness of the cathode electrode coating $D_{c}$ the investigated cell can be altered from a power oriented to an energy oriented cell.

\subsection{Energy and Power Calculation}

In order to determine the P/E-ratios dependent on cell designs, the calculations for energy and power are introduced in this section.

The energy of a lithium-ion cell is linearly related to the respective mass of active electrode material in the cell. In the investigations presented below a Nickel-Cobalt-Manganese Oxide (NMC-111) was assumed as the cathode material and graphite as the anode material. The initial capacity was considered $155 \mathrm{mAh} / \mathrm{g}$ for the NMC-111 and $350 \mathrm{mAh} / \mathrm{g}$ for the graphite [8]. Irreversible capacity was assumed between $5 \%$ and $10 \%$, whereas the active material share was considered larger than $90 \%$ of the total electrode mass [9]. The cell energy is then calculated by multiplying the cathode active material mass with the specific capacity and the first cycle efficiency.

The respective maximum power of the cell $P_{\max }$ was calculated by making use of the relation between the generated heat power $P_{\text {loss }}$ and dissipated heat power $\mathrm{P}_{\text {out }}$ (equation 2). The maximum cell power can be described as the product of the maximum current $I_{\max }$ and the voltage at e.g. $90 \%$ state of charge (SOC) $U_{S O C 90}$ minus $P_{\text {loss }}$ that occurs due the internal resistance of the cell.

$P_{\max }=U_{\text {SOC } 90} \times I_{\text {max }}-P_{\text {loss }}$

In the model, the area specific impedance $R_{\text {spec }, A}$ is assumed to be constant (equation 3). The impedance $\mathrm{R}_{1}$ is scaled by the ratio of the electrode surface $A_{l}$ to $A_{0}$. For the initial electrode surface $A_{0}$ a value of about $4 \mathrm{~m}^{2}$ was assumed. The initial internal resistance $R_{0}$ was $0,8 \mathrm{~m} \Omega$. Both data points stem from a prismatic automotive cell.

$R_{\text {spec }, A}=R_{0} \times A_{0}=R_{1} \times A_{1}$

$I_{\max }$ can be expressed as a relation of the internal resistance and the power loss. At the steady state of heat power generated by the internal resistance and dissipated heat power, the following equation 4 applies:

$P_{\text {out }}=P_{\text {loss }}=R_{i} \times I_{\max }^{2}$ 
This leads to the following expression of maximum power capability as a function of electrode surface and the dissipated heat.

$$
P_{\max }=U_{\text {SOC } 90} \times \sqrt{\frac{P_{\text {out }}}{R_{0} \times A_{0}} \times A_{1}}-P_{\text {out }}
$$

For the comparison of different cell formats one possibility would be to scale the dissipated heat power by the cooling surface of the respective cell format.

The introduced power calculation describes a special case in which the entire generated heat of the cell needs to be dissipated through the can surface. This limitation applies in the case that the cell reached the maximum acceptable temperature. For short peak power pulse the local hot spot temperature on the electrode surface would most likely be the only power limitation. Hence, further detailed thermal modelling could lead to relaxed power limitations for peak pulses.

\subsection{Premises Cost Data}

To determine the energy and power specific costs, each cell is described through a detailed BOM. To evaluate the cost of the cell, the BOM is connected to the data shown in Table 1. This cost data is taken from publications from the last three years [1]-[5].

Table 1: Exemplary lithium-ion cost data sources [1]-[5]

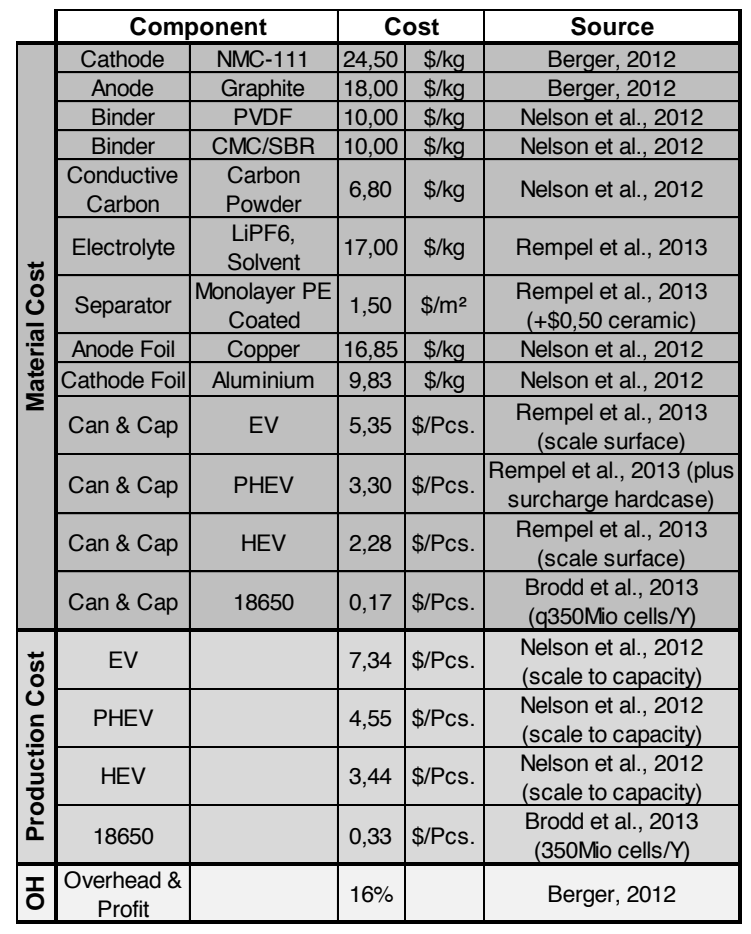

Considering vehicle projects with significant quantities in the future, the available cost data from scientific publications can be presumed conservative. Therefore, the lowest price out of these studies is considered for each item. The assumed conversion rate was $1,30 \$ / €$.

\subsection{Results Cell Model}

Through the cell model the relation between power, energy and specific costs dependent on the examined technology can be quantified. As shown in Figure 1, the relation between energy specific cost $c_{E-s p e c}$ and the power to energy ratio $(\mathrm{P} / \mathrm{E}-$ ratio) of the cell is approximately linear. The slope $m_{\text {tech }}$ and the y-axis intercept $b_{\text {tech }}$ are dependent on the investigated technology. These coefficients change e.g. for different cell formats or different active materials.

$$
c_{E-\text { spec }}=m_{\text {tech }} \times \frac{P}{E}+b_{\text {tech }}
$$

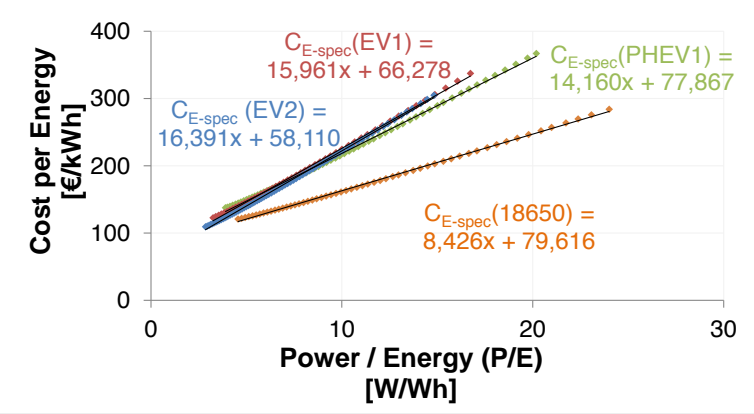

Figure 1: Exemplary relations between P/E-ratio and cost per energy for different cell formats

This linear approximation seems reasonable for a wide range of electrode thicknesses. Other publications show similar relations [5].

\section{Cost Impact on Vehicle Portfolio}

One of the key issues for cell and automobile manufacturers is the question how to address a wide range of requirements with a limited number of different components. Hence, the design and definition of modular component kits is indispensable for cost-competitiveness [10]. For an OEM the range of different battery requirements might stem from different vehicles in the product portfolio, for a cell manufacturer these might result from different customer specifications. In this section, a methodology is introduced which supports the identification of cost-optimal cell designs - not only for one specific vehicle but for a whole vehicle project portfolio. 


\subsection{Vehicle Portfolio}

The fictional vehicle portfolio is based on the segments in which vehicles with electrified drivetrains such as Nissan Leaf, VW eGolf, BMW i3, Tesla Model S and Fisker Karma are available today. The power and especially the energy requirements are expected to be higher in the future than those of today's vehicles. They are forecasted to the next three to five years - a typical timeframe for the vehicle development period [11]. In Table 2, the fictional specifications for eight vehicles ranging from compact (C-Segment) to luxury (F-Segment) automobiles are described.

Table 2: Exemplary Vehicle Portfolio

\begin{tabular}{|c|c|c|}
\hline \multicolumn{3}{|c|}{ Vehicle Projects } \\
\hline $\begin{array}{c}\text { Power (Battery) } \\
{[\mathrm{kW}]}\end{array}$ & $\begin{array}{c}\text { Energy (Battery) } \\
{[\mathrm{kWh}]}\end{array}$ & $\begin{array}{l}\text { Vehicle } \\
\text { Class } \\
\end{array}$ \\
\hline 100 & 25 & \multirow{3}{*}{$\begin{array}{c}\text { BEV } \\
\text { C-Segment }\end{array}$} \\
\hline 120 & 30 & \\
\hline 150 & 35 & \\
\hline 150 & 50 & \multirow{3}{*}{$\begin{array}{c}\text { BEV } \\
\text { D\&E } \\
\text { Segment }\end{array}$} \\
\hline 200 & 40 & \\
\hline 250 & 60 & \\
\hline 320 & 25 & $\begin{array}{c}\text { PHEV } \\
\text { F- Segment }\end{array}$ \\
\hline 400 & 85 & $\begin{array}{c}\text { BEV } \\
\text { F- Segment }\end{array}$ \\
\hline
\end{tabular}

The above mentioned requirements serve as input data for the determination of a cost-optimal cell design for a vehicle portfolio. In addition the planned vehicle quantities are important to consider, since the vehicle projects will have different impacts on the total cell cost. Therefore, the requirements need to be weighted by the respective planned vehicle volume.

\subsection{Single and multiple cell variant solutions}

In order to identify the cost-optimal cell design for multiple projects, the cost impact of oversizing energy and power needs to be understood.

In case 1, as depicted in Figure 2 the P/E-ratio of the vehicle requirement is larger than the $\mathrm{P} / \mathrm{E}$ ratio of the cell. The considered cell with the P/E-ratio $P / E_{\text {cell }}$ does not fulfil the power requirements of the vehicle $P_{v e h}$ at the point where the energy of the cells and the energy requirement of the vehicle have the same value. $\left(E_{\text {cell }}=E_{v e h}\right)$. Therefore the energy of the battery $E_{\text {cell }}$ needs to be oversized. In Figure 2 this would mean moving up the $P / E_{\text {cell }}$ line until $P_{c e l l}=P_{v e h}$.
In the actual battery, using the same $P / E_{\text {cell }}$, this can only be done by adding more cells.

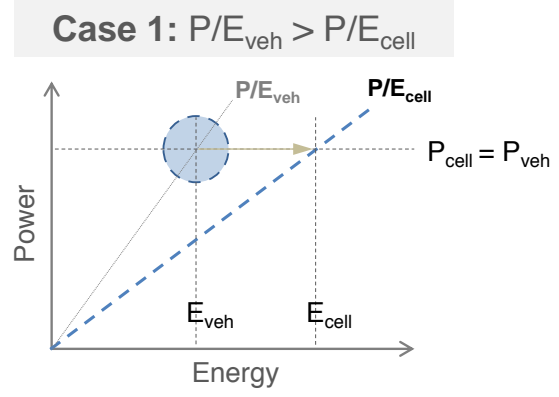

Figure 2: P/E-ratio of vehicle requirement is larger than of considered cell $\rightarrow$ Energy oversizing of a battery

For case 1, the cell cost for the considered vehicle project $c_{v e h}$ can be calculated by making use of the linear equation 6 for the energy specific cell cost. It is multiplied by the required energy $E_{v e h}$ in the vehicle and the planned vehicle quantity $Q_{v e h}$. The quotient of the P/E-ratios of the vehicle and the cell determines the degree of oversizing the energy of the vehicle.

$$
c_{\text {veh }}=\left(m_{\text {tech }} \times\left(\frac{P}{E}\right)_{\text {cell }} \times b_{\text {tech }}\right) \times E_{\text {veh }} \times Q_{\text {veh }} \times \frac{\left(\frac{P}{E}\right)_{\text {veh }}}{\left(\frac{P}{E}\right)_{\text {cell }}}
$$

In case 2, as shown in Figure 3 the P/E-ratio of the considered cell $P / E_{\text {cell }}$ is larger than the ratio of the vehicle power and energy requirements $P / E_{v e h}$. Therefore the power of the battery needs to be oversized in order to meet the energy requirements of the vehicle $E_{v e h}$.

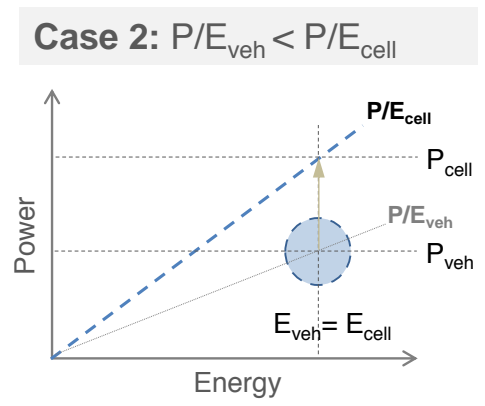

Figure 3: P/E-ratio of vehicle requirement is smaller than of considered cell $\rightarrow$ Power oversizing of a battery

In case 2 the cell cost of the considered vehicle project can be calculated by inserting the $\mathrm{P} / \mathrm{E}$-ratio of the cell in equation 6 and multiplying this term with the required vehicle energy $E_{v e h}$ and the planned vehicle quantity $Q_{v e h}$.

$c_{\text {veh }}=\left(m_{\text {tech }} \times\left(\frac{P}{E}\right)_{\text {cell }} \times b_{\text {tech }}\right) \times E_{v e h} \times Q_{v e h}$ 
For case 2, the oversizing of power is a result of implementing the $\mathrm{P} / \mathrm{E}$-ratio of the cell in the cost equation. In this case the P/E-ratio of the cell is larger than the P/E-ratio of the vehicle. This leads to higher cost per $\mathrm{kWh}$ (equation 6).

\subsection{Determination of Cost Minimum Number of Cell Variants}

From equation 7 and equation 8 it can be concluded that the cell cost minimum is reached when the P/E-ratio of the cell matches the P/E-ratio of the vehicle. In this case no oversizing, neither of energy nor of power is required.

This would potentially lead to a large number of cell variants, which is not favorable for cost reasons. Hence, a methodology is introduced which enables OEMs and cell suppliers to determine the cost-optimal number of cell variants and their respective $\mathrm{P} / \mathrm{E}$-ratios.

The ideal $\mathrm{P} / \mathrm{E}$-value of a cell serving multiple vehicle projects can be determined by making use of relations of equations 7 and 8 . The P/E-ratio of the cell should be adjusted in a way that the cost for oversizing power and energy is minimized.

To determine one cost-optimal cell for all $t$ vehicle projects the sum of the cost weighted distances $d_{n}$ between the cell's P/E-ratio and the vehicles' $\mathrm{P} / \mathrm{E}-$ ratios needs to be minimized.

$$
\min \sum_{n=1}^{t} \min d_{n}
$$

In order to identify the cost-optimal P/E-ratios for more than one cell serving the vehicle portfolio the minimum cost weighted distance $d_{n, j}$ needs to be identified by evaluation of power and energy oversizing to all $m$ cell variants.

$$
\min \sum_{n=1}^{t} \min _{1 \leq j \leq m} d_{n, j}
$$

In Figure 4 the comparison of energy oversizing for vehicle project 5 to the P/E-ratio of cell 2 and power oversizing to the P/E-ratio of cell 1 is illustrated. The vehicle projects are indicated by the blue circles. The center illustrates the planned combination of their respective power and energy requirement. The dotted lines show the two different P/E-ratios of the considered cells. Using the same cell type, the P/E-ratio of a battery pack will not be changed by increasing or reducing the number of integrated cells. As long as the same cell is used, an increase of the storable energy of a battery pack always leads to an increase of power.

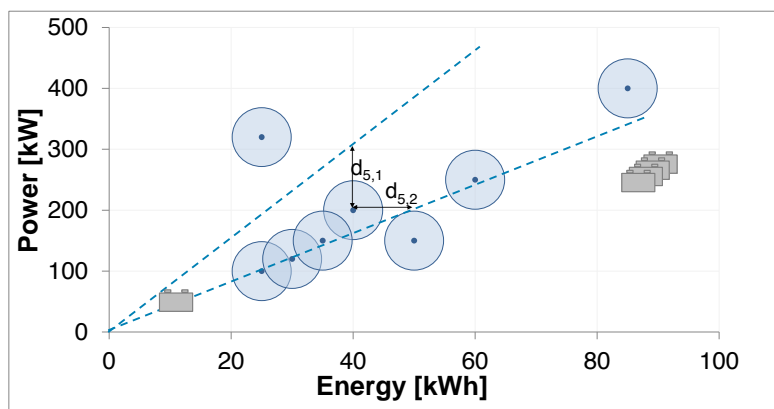

Figure 4: Power and energy oversizing comparison for more than one cell variant

The identification of cost minimal power or energy oversizing leading to the cost-optimal P/E-ratios for multiple cells requires a large number of computations. For the exemplary vehicle portfolio used in this paper, the P/E-ratios of the vehicle portfolio range from 3,0 to 12,8 . As the achievable production precision of electrode thickness and porosity is limited [12] the minimum step width of $\mathrm{P} / \mathrm{E}$-ratios is assumed 0,1. This leads to 67,91 million combinations of $\mathrm{P} / \mathrm{E}-$ ratios if 5 cell variants are considered for the vehicle portfolio. Hence 2,72 billion operations would be needed to compare the 8 vehicle projects to the $5 \mathrm{P} / \mathrm{E}$ variants in order to identify the cost minimum.

Due to this complexity and the intention to further expand the calculation to account for additional restrictions of the battery design, identifying a suitable and fast algorithm was essential. As heuristic methods such as genetic algorithms (GA) quickly limit the solution space as they learn which parameters influence the fitness of the optimization criteria, they seemed promising for this application. In addition, GAs are capable of handling discontinuous relations which becomes relevant to account for battery design restrictions. The chosen GA program was GAnetXL [13]. The $\mathrm{P} / \mathrm{E}$-ratios of the considered cells were varied and used as the chromosomes in the optimization. The optimization criterion was the total cell cost of the vehicle portfolio taking into account all vehicle quantities. Figure 5 shows the exemplary result of an optimization using four $\mathrm{P} / \mathrm{E}$ variants.

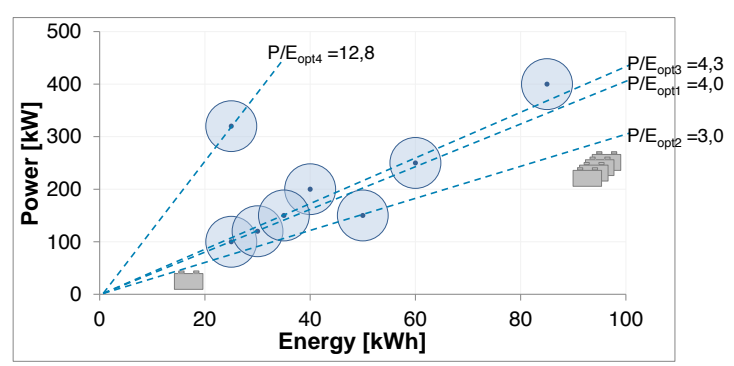

Figure 5: Exemplary result for multiple P/E-variants 
It can be seen that the lowest $(3,0)$ and highest P/E-ratio $(12,8)$ of the vehicle requirements in the portfolio are among the optimal cell configurations.

In the next step the cost-optimal number of different P/E-ratios is quantified. In Figure 6 the total lifetime cell costs for the full vehicle portfolio depending on the number of P/Edesigns are displayed. It can be concluded that four P/E-ratios are the cost-minimum for the considered vehicle portfolio (Table 2) considering an additional one-time expense per

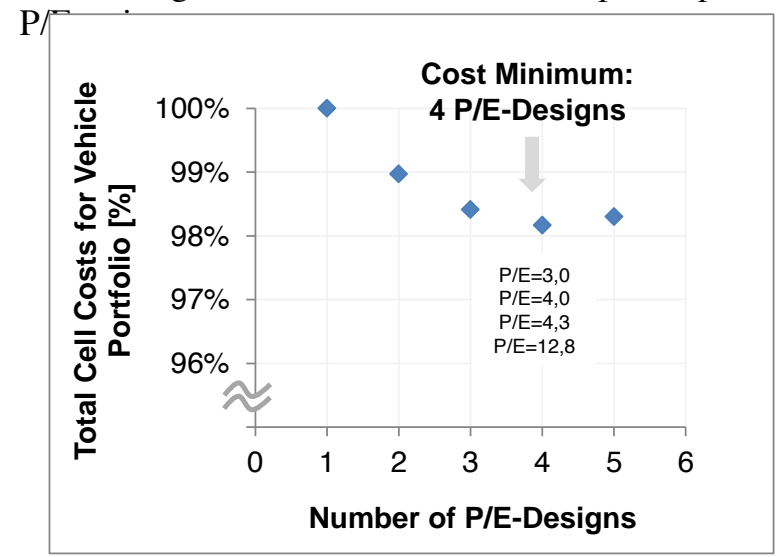

Figure 6: Exemplary determination of optimal number of P/E-ratios for the vehicle portfolio

The optimal number of P/E-variants heavily depends on the planned vehicle quantities and the actual amount of one-time expenses that occurs at the cell manufacturer for development and at the OEM for validation of an additional cell variant. The degree to which the power and energy requirements differ from vehicle to vehicle is of influence for the ideal number of P/E-ratios as well. As the cost impact of the number of P/E-designs relates to a full vehicle portfolio the decision for the right number can be easily in the tens of million Euros depending on the vehicle quantities.

\subsection{Cost Impact of Voltage Restriction in Electrified Drivetrains}

An important restriction for the integration of lithium-ion batteries into electrified drivetrains is the limitation of the voltage that can be handled by the inverter. The upper voltage limit is mainly determined by the availability of insulated-gate bipolar transistors (IGBTs). Currently IGBTs commonly used in electric vehicles have an upper operating voltage limit of $600 \mathrm{~V}$. Including safety margins for voltage peaks after switching and provisions for the voltage variation over the SOC of a lithium-ion battery this restricts the maximum nominal voltage level (i.e. $50 \%$ SOC) in the battery to around $400 \mathrm{~V}$. The lower voltage limit of the battery is mainly restricted by the power requirement and the current limitation of the cell. In order to meet lifetime and safety requirements cell manufacturers set current limits for the cells. For a lithium-ion cell the open circuit voltage significantly drops over the SOC (e.g. for a NMC-111 / graphite cell from 4,1 V to $2,7 \mathrm{~V}$ ). Hence, the current needs to be increased at lower SOCs to meet power requirements at the reduced voltage level. A typical lower voltage limit of an automotive battery pack is $300 \mathrm{~V}$ [14].

These upper and lower voltage limitations of the battery pack influence the pack design as they limit the number of cells that can be connected in series. As the nominal voltage level of an NMC-111/ graphite cell is approximately $3,7 \mathrm{~V}$ the described voltage restrictions lead to a limitation of 80 to 108 cells connected in series. The cell specific voltage level depends on the potential between the used anode and cathode material. It is not influenced by the cell capacity or cell size. If more than 108 cells need to be integrated into the battery pack, than a second series of cells would be needed to be integrated into the vehicle. This implies that the next bigger battery pack needs to consist at least of 160 cells $(2 \times 80$ cells in series connection). All storage capacities between 108 and 160 cells do not fulfill voltage requirements.

The solution spaces for one, two and three cells in a parallel electric connection are shown in Figure 7 for the EV2-format. In this case the vehicle portfolio is served with only one P/E-ratio.

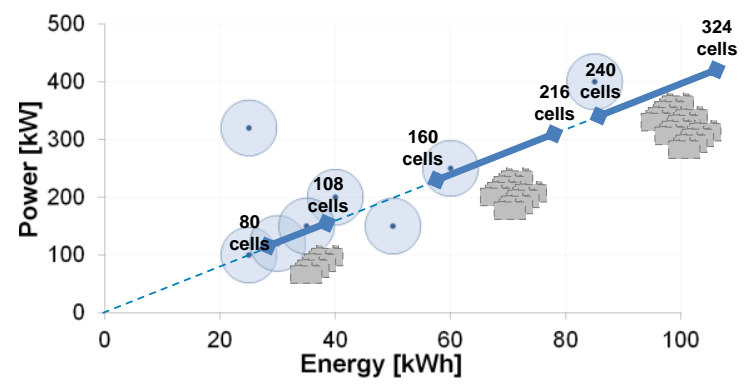

Figure 7: Impact of voltage limitation on scalability of battery size (EV2 cell, $\mathrm{P} / \mathrm{E}=4)$

Figure 8 illustrates how the solution space (light blue) would change if different P/E-ratios would be added. Using the same large EV2-format still large uncovered areas in the solution space would remain. These areas are dependent on the cell size. Adding more P/E-ratios does not lead to coverage of the full solution space. 
For vehicle requirements in the white area, the battery pack would possibly need to be oversized two times:

1) by adding cells to meet energy and power requirements (distance to the P/E-line of the considered cell - black arrow),

2) by adding cells to meet the voltage requirement (distance to the next blue solution area - red arrow).

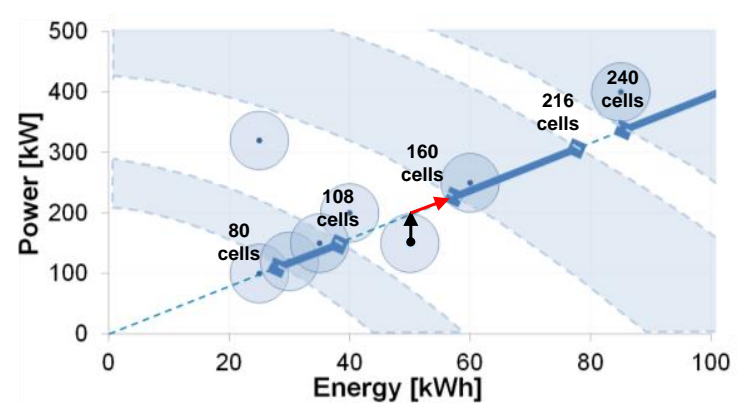

Figure 8: Solution areas of EV2 cell considering voltage limitation $(300 \mathrm{~V}-400 \mathrm{~V})$

In Figure 9 the same portfolio of vehicle requirements is served with the smaller cell format EV1. Compared to Figure 8 the blue solution area becomes larger, as the capacity per cell decreases due to the smaller cell volume. For more than 320 cells $(4 \times 80$ cells $)$ the solution space of three and four parallel connected cells overlaps.

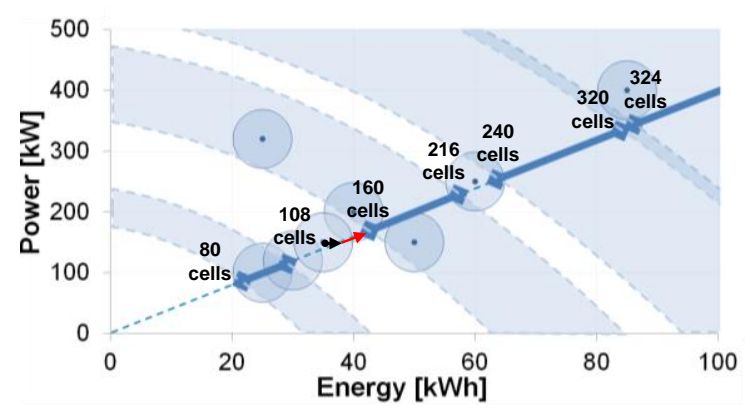

Figure 9: Solution areas of EV1 cell considering voltage limitation $(300 \mathrm{~V}-400 \mathrm{~V})$

Although smaller cells show an advantage regarding their scalability, the cost-optimal cell size needs to be determined case by case. Some vehicle projects in the C-Segment with potentially significant quantities are outside the solution space of the EV1 cell, which were within the blue solution space of the larger EV2 cell. In addition a project specific comparison of cell formats is necessary because larger prismatic cell formats show a lower cost per energy as shown in Figure 10. They contain a smaller share of passive material and have lower production costs, as fewer large cells are necessary to make up for one kWh [7]. Based upon the exemplary cost data of Table 1 the 18650-format has a cost advantage, due to its simple and less expensive housing format and production concept.

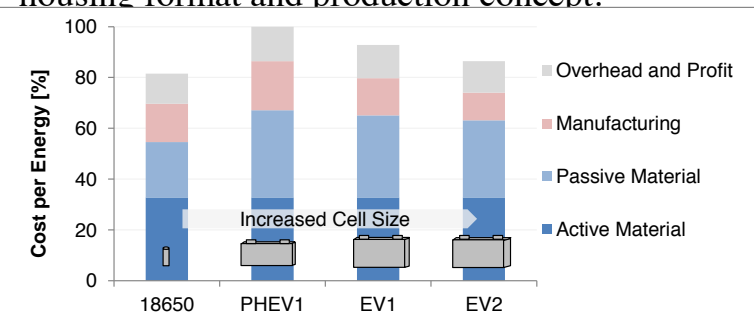

Figure 10: Exemplary energy specific cost for different cell sizes $(\mathrm{P} / \mathrm{E}=$ const; cell illustrations not to scale $)$

In order generate a quantitative assessment of the cost-optimal cell format a comparison of the total cell cost as shown in Figure 11 is necessary. Using the cost-optimal number of P/E-variants, the total cell cost of the different formats is determined. The light blue bar represents the total cell cost of the portfolio not taking into account the voltage restriction of the battery system (stand-alone cell cost). Even though this can be considered a theoretical value, it represents the cell costs which are investigated in many publications [1]-[5]. Considering the application of the cell in the vehicle, the cost impacts of limitations on the battery system level have to be taken into account as well. The increased costs caused by the voltage restrictions are represented by the dark-blue bars. These costs are larger than the stand-alone cell costs if oversizing of the batteries is required to fulfil voltage restrictions of the drivetrain system. They are on the same level as the stand-alone cell costs if no oversizing of the batteries is required to fulfil voltage limitations. Figure 11 shows the 18650-format as the most cost efficient cell for the investigated vehicle portfolio considering the exemplary cost parameters of Table 1 . As a result of its simple housing design, the 18650 -format has the lowest stand-alone cell cost. At the same time no oversizing of the battery is necessary as voltage restrictions do not impact the integration of the 18650 -format due to its small size. The larger cell formats EV2 and EV1 show a significant deviation between stand-alone cell cost and cell cost on the system level taking into account the voltage limitation. Contrary to initial expectation this deviation is even bigger for the EV1-format than for the larger EV2-format. The reason for the cost disadvantage of EV1-format for this particular vehicle portfolio can be found in the C-Segment vehicle projects with potentially significant quantities outside the solution area. Using the 
smaller PHEV1-format, the battery scaling is already sufficient to create a solution space that is large enough to avoid battery oversizing to reach voltage requirements. Therefore, the cost increase due to the voltage limitation is minimal for the PHEV1-format. The disadvantage of this format is the comparably high stand-alone cell cost. Can and cap cost of prismatic cells lead to a

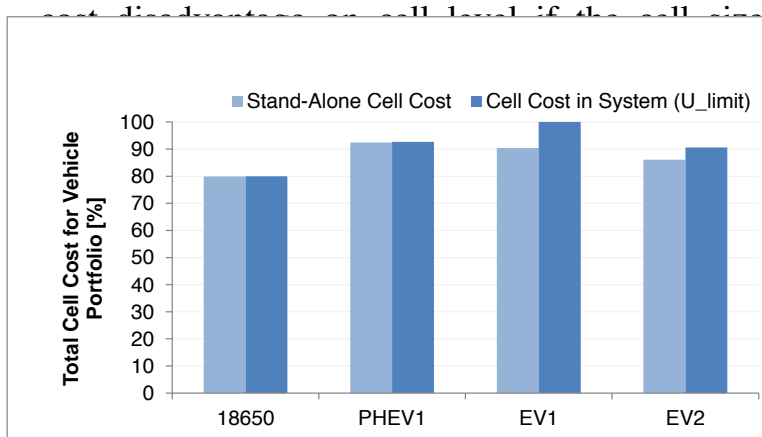

Figure 11: Exemplary total cell cost of vehicle portfolio for different cell formats

\section{Summary of Finding and Outlook}

In order evaluate the optimal cell cost for a vehicle portfolio this paper introduced a cell model which describes the relations between cost and function of a lithium-ion cell dependent on the chosen technology parameters. Based on the bill of material of this model the cell costs were quantified. The lowest cost per function can be reached when the P/E-ratio of the cell matches the P/E-ratio of the vehicle. In this case, neither power nor energy of the battery has to be oversized to meet vehicle requirements. Considering a vehicle portfolio, this finding would potentially lead to large number of different cell variants. Hence, an algorithm to identify the cost-optimal number of different cell designs and their respective $\mathrm{P} / \mathrm{E}$-specifications was applied. The cost impact of the number of $\mathrm{P} / \mathrm{E}$-variants was found to be significant, dependent on the one-time expense, the planned vehicle quantities and the distribution of $\mathrm{P} /$ E-requirements in the vehicle portfolio.

In the final part of the paper, not only the standalone cell costs were considered, but the cell cost impact of a battery system constraint has been taken into account as well. For the integration of lithium-ion cells into electric drivetrains the operating voltage levels of the battery pack are restricted due to voltage limits of the inverter and current limits of the cell. In general, it can be anticipated from the investigations that smaller cells are less prone to cost increase due to oversizing of the battery in order to reach voltage limitations. However, a decrease of cell size leads to an increase of energy specific cost due to higher cost share of the housing. Based on the cost data assumed this effect was small for cylindrical cells and led to a cost advantage of this format even for smaller sizes. The study on the exemplary vehicle portfolio showed that a case by case investigation dependent on the requirements and quantities of a certain vehicle portfolio is indispensable to identify the cost-optimal cells.

Further investigation is going to be conducted to analyze the sensitivity of a cost-optimal cell design depending on the planned vehicle volumes, the power and energy requirements and the assumed cost-parameters. In this continuation of research alternative approaches for power calculation will be evaluated as well. Simulations to determine the sensitivity are necessary as the market for electric drivetrains is still small and precise forecasts of the quantities and types of electric vehicles desired in the future are hard to anticipate. Therefore, it is important to not only consider cost efficiency but to also factor in the cell type's robustness against changing requirements and uncertain vehicle planning quantities. Furthermore, future investigations should challenge the distinct separation of vehicle requirements and technical solution that is currently applied. From an economic standpoint it might be more attractive to oversize the battery or adapt the requirements depending on price sensitivity to vehicle range and power.

\section{References}

[1] Roland Berger Strategy Consultants, Lithiumion batteries - The bubble bursts. Stuttgart. 2012.

[2] Brodd, R. and Helou, C., Cost comparison of producing high-performance Li-ion batteries in the U.S. and in China. Journal of Power Sources, Vol. 23(2013), 293-300.

[3] Nelson, P., Gallagher, K., Bloom, I. and Dees, D., Modelling the Performance and Cost of Lithium-Ion Batteries for Electric-Drive Vehicles - Second Edition. ANL-12/55. Chemical Sciences and Engineering Division Argonne National Laboratory. Argonne, IL. 2012.

[4] Rempel, J., Barnett, B. and Hyung, Y., PHEV Battery Cost Assessment. TIAX, DOE Merit Review, 2013. 
[5] Sakti, A., Michalek, J.-J., Fuchs, E. and Whitacre, J.F., A techno-economic analysis and optimization of Li-ion batteries for lightduty passenger vehicle electrification. Journal of Power Sources, Vol. 273(2014), 966-980.

[6] Deutsches Institut für Normung e.V., Elektrische Straßenfahrzeuge -

Batteriesysteme - Abmessungen für LithiumIonen-Zellen. DIN SPEC 91252:2011-01 (D), 2011.

[7] Tschech, M. and Vietor, T., Strategien zur Kosten- und Gewichtsoptimierung von Lithium-Ionen Zellen in Fahrzeuganwendungen. In: Symposium Faszination Leichtbau. ISBN 978-3-93765533-8, 2014, 127-147.

[8] Ozawa, K., ed., Lithium Ion Rechargeable Batteries: Materials, Technology, and New Applications. ISBN 978-3-527-31983-1. John Wiley \& Sons, 2009.

[9] Chen, Y., Wang, C., Zhang, Y. and Sastry, A. Porous cathode optimization for lithium cells: Ionic and electronic conductivity, capacity, and selection of materials. Journal of Power Sources 195 (2010). 2851-2862.

[10] Krumm, S., Schopf, K. D., and Rennekamp, M., Komplexitätsmanagement in der Automobilindustrie-optimaler Fit von Vielfalt am Markt, Produktstruktur, Wertstrom und Ressourcen. Automotive Management, ISBN 978-3-642-34067-3,189-205, Springer Berlin Heidelberg, 2014.

[11] Braess, H.-H., et al., Produktentstehungsprozess, In: Braess, H.-H. and Seiffert, U.(eds.), Handbuch Kraftfahrzeugtechnik, ISBN 978-3-65801691-3, Wiesbaden, Springer Fachmedien, 2013, 1133-1219.

[12] Pettinger, K.-H., Prüfverfahren in der Fertigung, In: Korthauer, R. (ed.), Handbuch Lithium-Ionen-Batterien, ISBN 978-3-64230652-5, 2013, 259-267.

[13] Savić, D. A., Bicik, J., and Morley, M. S. A DSS Generator for Multiobjective Optimization of Spreadsheet-Based Models. Environmental Modelling and Software, Vol. 26, No. 5(2011), 551-561.

[14] Kuchenbuch, K., Methodik zur Identifikation und zum Entwurf packageoptimierter Elektrofahrzeuge, Dissertation, TU Braunschweig, ISBN 978-3-8325-3262-8, 2012.

\section{Authors}

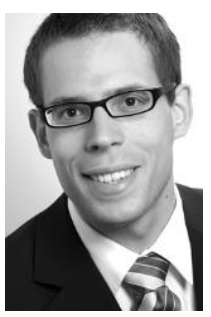

Matthias Tschech is a $\mathrm{PhD}$ student at the Institute for Engineering Design at TU Braunschweig and works as a cost engineer for an automotive OEM. His research focusses on the cost optimization of lithium-ion cells with respect to vehicle requirements and electric drivetrain integration. Matthias Tschech earned a Diplom Wirtschaftsingenieur degree focusing on automotive engineering from TU Braunschweig and an MBA from the University of Rhode Island.

Professor Dr.-Ing. Thomas Vietor is dean of the mechanical engineering department and head of the Institute for Engineering Design at TU Braunschweig. His research focusses on vehicle concepts and design methodology. Professor Dr.-Ing. Vietor earned his $\mathrm{PhD}$ degree from University of Siegen in the field of structural optimization. He hold several positions in engineering and management in the automotive industry. 